\title{
Effect of Silicon Content and Shake-Out Time on Hardness and Grain Size Properties of GL 250 Cast Iron
}

\author{
P. Atanda ${ }^{1}$, G. Oluwadare ${ }^{2}$ and O. Oluwole ${ }^{* 3}$ \\ ${ }^{\mathbf{1}}$ Materials Science and Engineering Dept.,Obafemi Awolowo University, Nigeria \\ ${ }^{2}$ Industrial Chemistry Department,Bells University, Nigeria. \\ ${ }^{3}$ Mechanical Engineering Dpartment,University of Ibadan, Nigeria \\ *Corresponding Author:oluwoleo2@asme.org
}

\begin{abstract}
The properties of cast iron grade GL 250 are dependent on the microstructures developed during casting. These microstructures are in turn dependent on the composition of the alloy, type of mould and other numerous casting practice variables such as shake-out time, pouring temperature, mould ambient conditions and inoculating technique.

In this work, the effect of silicon content and shake-out time on the grain size (GS) and hardness properties of GL 250 cast iron was studied using a pouring temperature of $1400^{\circ} \mathrm{C}$ and sand mould casting. Using charge materials consisting of pig iron and other additives, GL 250 castings containing silicon contents of 1.7, 2.1 and 2.7\% were casted using a constant pouring temperature of $1400^{\circ} \mathrm{C}$, molding sand of specified properties and ambient mould temperature of $32^{\circ} \mathrm{C}$.
\end{abstract}

Results showed that type A flake type was obtained at 30mins shakeout time for all samples for the C.I composition under study. Increasing shake-out time decreased hardness and increased carbide grain size. Increasing silicon content was observed to increase grain size and reduce free graphite but with resultant decrease in hardness. Two mathematical relationships were derived. One related grain-size to silicon content and shakeout time while the second related Brinnel Hardness to Silicon content and shake-out time. They are: Grain Size $=0.40$ Si+0.17Shake-out Time-0.15 and BHN=-60.53Si-7.15Shake-out Time+329.35 at $1400^{\circ} \mathrm{C}$ pouring temperature in a molding sand of specified properties and sand mould ambient temperature of $32^{\circ} \mathrm{C}$.

Keywords: Shake-out time; Silicon content; Hardness; Grain-Size; GL 250 C.I 


\section{INTRODUCTION}

Cast irons are widely used today in every sphere of life. Cast iron is an iron alloy characterized by its relatively high carbon content (usually $2 \%$ to $4 \%$ ). When molten cast iron solidifies some of the carbon precipitates as graphite, forming tiny, irregular flakes within the crystal structure of the metal (Walton,1958). While the graphite enhances the desirable properties of cast iron, the flakes disrupt the crystal structure and precipitate cracks, leading to cast iron's characteristic brittleness. White cast iron, gray cast iron and ductile iron are still massively in use today. In nodular cast iron the disadvantage opened up by free flakes in the cast matrix have been overcome, the free flakes having been nodularized with magnesium, or cerium and recent developments show that cheaper nodularization could be made with a combination of magnesium and calcium [1,2]. Gray iron is the most widely used, with annual production several times total of all other cast metals. It has excellent machinability, good wear resistance, and high vibration absorption [3]. Gray iron is valued particularly for its ability to be cast into complex shapes at relatively low cost. Thus, its application includes: sanitary wares, household appliances, rolling mill and general machinery parts, ingot moulds, cylinder blocks and heads for I.C. engines, frames for electric motors, machine tool structures, etc. [4]GL 250 grade of cast iron (or ASTM A-247 or DIN 1671) is a grade of grey iron with type A4-A7 graphite flakes having uniform distribution and apparent random orientation [5]. Mould material, inoculation, and shake-out time are some of the casting variables that affect the grain size of the as cast product. This work focused on the effect of shake-out time on hardness and grain size properties of GL 250 cast iron.

\section{MATERIALS AND METHODS}

\subsection{Materials}

\subsubsection{Charge composition for GL 250 cast iron}

The GL 250 Cast iron was cast from starting materials with composition as shown below in Table 1.

Melting was done using a coreless induction furnace of 250kg capacity and power rating of $250 \mathrm{kw} / 1000 \mathrm{~Hz}$. After melting the spectrometric analysis of the melt was obtained and is presented in Table 2.

\subsubsection{Innoculant}

Ferrosilicon was used as innoculant; introduced into the melt just before tapping of the liquid metal. 100g innoculant was used for every $250 \mathrm{~kg}$ ladle. 
Table 1: Material Charge Composition

\begin{tabular}{|c|c|c|c|c|c|c|c|}
\hline \multirow[b]{2}{*}{ Material } & \multicolumn{7}{|c|}{ Composition } \\
\hline & C & Si & $\mathrm{Mn}$ & $\mathrm{P}$ & $S$ & $\mathrm{Cu}$ & Sn \\
\hline Pig iron & 4.0 & 2.2 & 0.8 & 0.9 & 0.8 & - & - \\
\hline $\begin{array}{l}\text { Cropped Ends } \\
\text { From rolling } \\
\text { mill } \\
\end{array}$ & 0.23 & 0.2 & 0.5 & - & - & 0.3 & - \\
\hline \begin{tabular}{|l|} 
Foundry \\
Returns \\
\end{tabular} & 2.9 & 2.9 & 0.9 & - & - & 0.3 & 0.04 \\
\hline Carburizer & 99.3 & 0.1 & - & - & - & - & - \\
\hline Ferrosilicon & 0.1 & 75.0 & - & - & - & - & - \\
\hline $\begin{array}{l}\text { Ferro- } \\
\text { manganese }\end{array}$ & 0.1 & - & 75.0 & - & - & - & - \\
\hline Copper & - & - & - & - & - & 99.1 & - \\
\hline Tin & - & - & - & - & - & - & 99.1 \\
\hline
\end{tabular}

Table 2: Spectrometric Analysis of As-Cast GL250 Cast Iron

\begin{tabular}{|l|l|l|l|l|l|l|}
\hline \multicolumn{7}{|c|}{ Composition } \\
\hline $\mathrm{C}$ & $\mathrm{Si}$ & $\mathrm{Mn}$ & $\mathrm{P}$ & $\mathrm{S}$ & $\mathrm{Cu}$ & Sn \\
\hline 3.3 & 2.1 & 0.68 & 0.09 & 0.09 & 0.25 & 0.05 \\
\hline
\end{tabular}

\subsubsection{Moulding sand}

Moulding sand used comprised of Nigerian moulding sand mixtures ( 70\% Igbokoda and 30\% Basita sands). The moulding sand was subjected to standard tests: Sand finess number (AFS), Permeability, Mould Strength, Moisture Content, Clay Content, Shatter Index and Sand Strength Tests. The results are presented in Table 3.

\subsection{Method}

\subsubsection{Casting}

Five sand moulds of auto flywheels were made using a Peugeot 504 auto flywheel, giving the flywheel some rapping for ease of removal from the moulds. The charge materials were then input into a $250 \mathrm{~kg}$ capacity coreless induction furnace for melting. Just before tapping, ferrosilicon was added as innoculant. Innoculation is believed to have important effect on the formation of graphite nuclei during solidification, thus influencing the resulting structure and 
strength of casting[4,6]. The metal was poured into the five moulds and left for 12 mins, 30 mins, $1 \mathrm{hr}$, 5hrs and 10hrs before shake-out. This procedure was repeated for melts having silicon contents of $1.7 \%$, and $2.7 \%$. Pouring temperature was fixed at $1400^{\circ} \mathrm{C}$. Specimens from the castings were then prepared for microstructureobservation.

Table 3: Results of Tests on Moulding Sand

\begin{tabular}{|l|l|l|l|l|l|l|l|l|l|}
\hline \multirow{2}{*}{ AFS } & \multirow{2}{*}{$\begin{array}{l}\text { Permeab } \\
\text { ility }\end{array}$} & $\begin{array}{l}\text { Mould } \\
\text { Strength } \\
\left(\mathrm{N} / \mathrm{m}^{2}\right)\end{array}$ & $\begin{array}{l}\text { Moisture } \\
\text { Content } \\
(\%)\end{array}$ & $\begin{array}{l}\text { Clay } \\
\text { Content }\end{array}$ & $\begin{array}{l}\text { Shatter } \\
\text { Index }\end{array}$ & $\begin{array}{l}\text { Green } \\
\text { comp }\end{array}$ & $\begin{array}{l}\text { Green } \\
\text { Shear }\end{array}$ & $\begin{array}{l}\text { Dry } \\
\text { Comp }\end{array}$ & $\begin{array}{l}\text { Dry } \\
\text { Shear }\end{array}$ \\
\hline 62 & 125 & 80 & 3.0 & 1.5 & 85 & 112 & 38 & 660 & 370 \\
\hline
\end{tabular}

\subsubsection{Metallographic examination}

Specimens were prepared for metallographic examination by using standard grinding and polishing methods [7-12]. Polished and etched samples were observed under an optical microscope with camera attachment at X100 magnification to assess the microstructure developed in the casting with varying shake-out times; the type of carbides and graphite flakes formed and the grain size of the carbides.

Photomicrographs of the observed microstructures were taken. The linear intercept method for grain size measurement was employed. Flake type was obtained using AFA and ASTM graphite flakes classification [13].

\subsubsection{Hardness measurement}

Brinnel hardness tests were carried out on samples of the castings.

\section{RESULTS AND DISCUSSION}

\subsection{Results}

Optical micrographs of Cast Iron containing 1.7\% , 2.1\% and 2.7\% Si for shake-out times of 12 mins, 30 mins, $1 \mathrm{hr}, 5$ and $10 \mathrm{hrs}$ are presented in Figure1. It was observed that there was less free graphite with increasing silicon content. Grain size was observed to increase as well with increasing silicon content. 


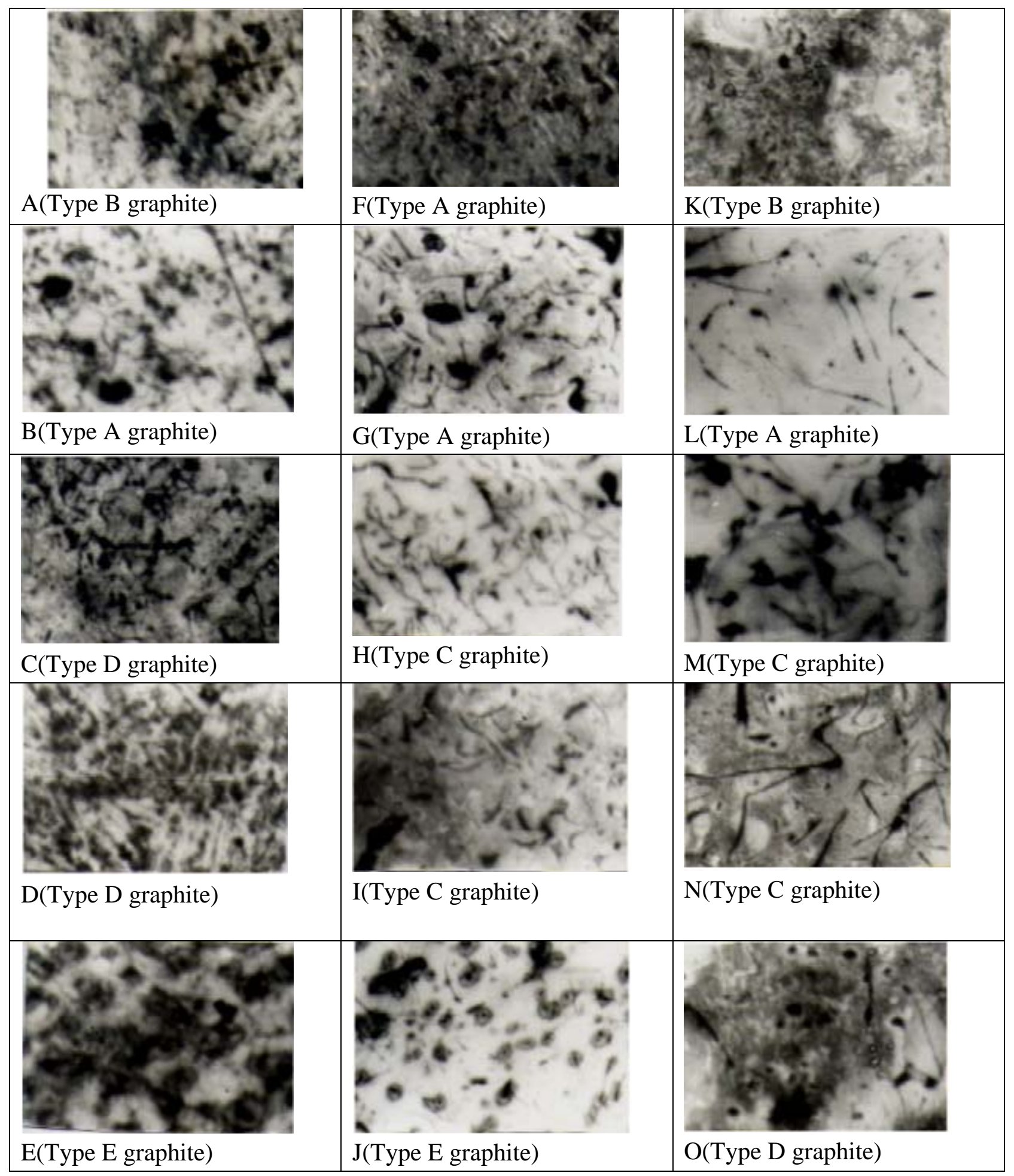

Fig.1: Optical micrographs of GL 250 cast in sand mould. Pouring Temperature- $1400^{\circ} \mathrm{C}$ X100 A-E-Cast Iron containing1.7\% Si. (A=12mins,B=30mins, C=1hr,D=5hrs, E=10hrs)

F-J-Cast iron containing $2.1 \% \mathrm{Si}(\mathrm{F}=12, \mathrm{G}=30 \mathrm{mins}, \mathrm{H}=1 \mathrm{hr}, \mathrm{I}=5 \mathrm{hrs}, \mathrm{J}=10 \mathrm{hrs})$ $\mathrm{K}-\mathrm{O}$-Cast iron containing $2.7 \% \mathrm{Si}(\mathrm{K}=12, \mathrm{~L}=30 \mathrm{mins}, \mathrm{M}=1 \mathrm{hr}, \mathrm{N}=5 \mathrm{hrs}, \mathrm{O}=10 \mathrm{hrs})$ 
Figures 2 and 3 present the plots of shake-out time on grain size and hardness respectively with varying silicon content of the cast iron. It was observed that grain size increased with increasing shake-out time. Hardness decreased with increasing shake-out time. Increasing silicon content of the cast iron was observed to increase grain size of carbide while decreasing hardness. The values of variation of grain size and hardness with shake-out time for $1.7 \%, 2.1 \%$ and $2.7 \% \mathrm{Si}$ content Cast iron are presented in Tables 4-6 respectively.

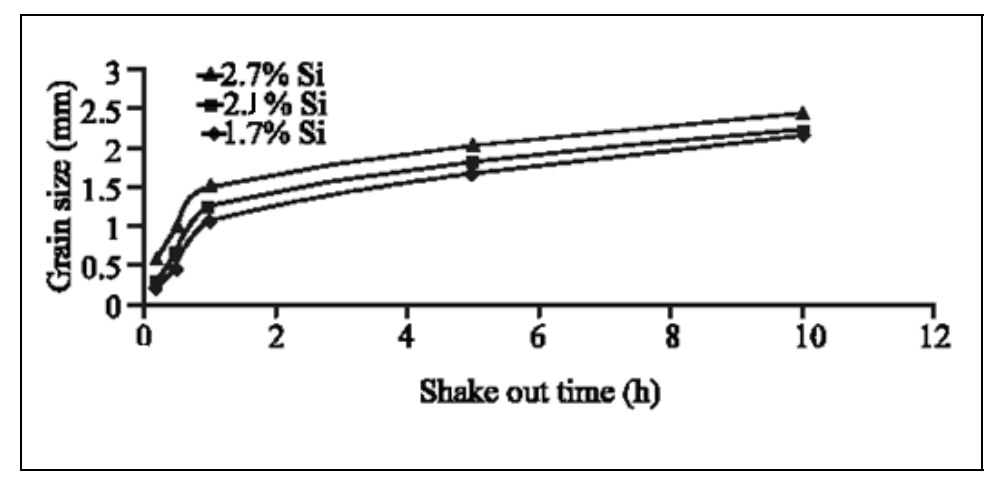

Fig.2: Plot of effect of shake-out time on grain size

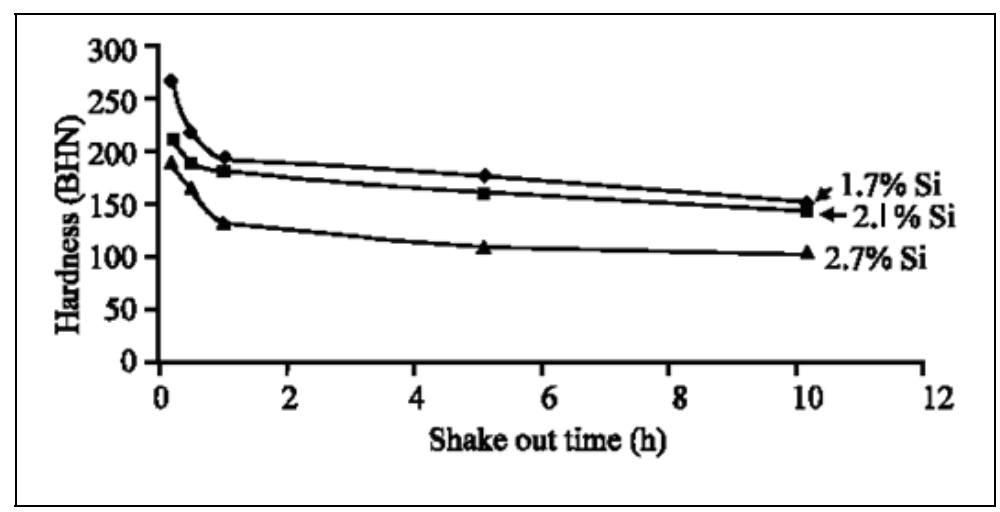

Fig.3:Plot of effect of shake-out time on hardness

Table 4: Effect of Shake-out Time on Hardness and Grain-size for Casting with $1.7 \mathrm{Wt} \% \mathrm{Si}$ Content

\begin{tabular}{|l|l|l|}
\hline $\begin{array}{l}\text { Shake-out Time } \\
\text { (Hrs) }\end{array}$ & Grain-size(mm) & BHN \\
\hline 0.2 & 0.20 & 268 \\
\hline 0.5 & 0.45 & 220 \\
\hline 1.0 & 1.05 & 196 \\
\hline 5.0 & 1.66 & 178 \\
\hline 10.0 & 2.14 & 152 \\
\hline
\end{tabular}


Table 5: Effect of Shake-out Time on Hardness and Grain-size for Casting with $2.1 \mathrm{Wt} \% \mathrm{Si}$ Content

\begin{tabular}{|l|l|l|}
\hline $\begin{array}{l}\text { Shake-out Time } \\
(\text { Hrs })\end{array}$ & Grain-size(mm) & BHN \\
\hline 0.2 & 0.30 & 211 \\
\hline 0.5 & 0.66 & 190 \\
\hline 1.0 & 1.23 & 183 \\
\hline 5.0 & 1.81 & 161 \\
\hline 10.0 & 2.22 & 145 \\
\hline
\end{tabular}

Table 6: Effect of Shake-out Time on Hardness and Grain-size for Casting with $2.7 \mathrm{Wt} \% \mathrm{Si}$ Content

\begin{tabular}{|c|c|c|}
\hline $\begin{array}{c}\text { Shake-out Time } \\
\text { (Hrs) }\end{array}$ & Grain-size(mm) & BHN \\
\hline 0.2 & 0.56 & 190 \\
\hline 0.5 & 1.00 & 168 \\
\hline 1.0 & 1.48 & 135 \\
\hline 5.0 & 2.01 & 112 \\
\hline 10.0 & 2.43 & 106 \\
\hline
\end{tabular}

\subsection{Discussion}

\subsubsection{Variation of grain-size with shake-out time}

Observations from Figs. 1 and 2 showed that the finest microstructures are obtained in short shake-out time [14,15]. For the different values of silicon addition to melt, it was observed that at 30mins shake-out time, type A flakes were obtained for all the materials. At all the other shakeout times, flake types were of other grades than A. As shakeout time progressively increased for the varying percentages of silicon addition, grain size increased and consequently the pearlite-ferrite distribution (Figs. 1B-E, G-J and L-O). Therefore choice of appropriate shake-out time is critical in developing the right microstructure for different applications to which GL 250 Cast Iron is made use. For example, auto brake-drum applications requiring type A graphite must have controlled shake-out time. Gray iron composition must be strictly controlled for different applications desired. For example the brake drum needs a Nickel addition of about $1.25 \%$ and chromium of $0.5 \%$ [13].

\subsubsection{Variation of grain-size with silicon content}


Grain size was observed to increase with increasing silicon content of melt. Grain size in Fig. 1B was smaller than Fig.1G which was also smaller than Fig.1 L . The same was observed in Figs. $1 \mathrm{C}, \mathrm{H}$ and $\mathrm{M}$. Grain size of $1 \mathrm{D}<1 \mathrm{I}<1 \mathrm{~N}$ and Grain size of $1 \mathrm{E}<1 \mathrm{~J}<1 \mathrm{O}$. These are also observed in Fig.2.

\subsubsection{Variation of hardness with shake-out time}

The hardness property of the casting was observed to follow an inverse relationship with increase in shake-out time (Fig.3). With increasing silicon content of casting, hardness was observed to decrease as well (Fig. 3)

\subsubsection{Variation of hardness with shake-out time and silicon content}

From Tables 4, 5 and 6 it was observed that increase in grain-size led to a decrease in hardness of the casting for all the values of silicon content used in the casting. It was also observed that hardness decreased with increasing silicon content of the cast iron.

3.2.5 Derivation of equation relating shake-out time to silicon content, grain-size and hardness properties of GL 250 cast iron using moulding sand and pouring temperature of $1400^{\circ} \mathrm{C}$.

The parameters varied; shake-out time and silicon content and the measured properties; grain size and hardness were linked up with shake-out time in two predictive equations by using multiple regression analysis. Microsoft excel was used in the regression analysis. Placing Grainsize and Brinnel Hardness as unknowns, with two known values-silicon content, and shake-out time two equations were obtained as given:

\section{Grain Size=0.40 Si+0.17Shake-out Time-0.15}

BHN=-60.53Si-7.15Shake-out Time+329.35

With these equations, shake-out time could be determined with preset Grain size or Brinnel Hardness. Combining both equations give:

\section{Shake-outTime=6.85Grain-size-0.017Si+0.045BHN-13.19}

\section{CONCLUSION}

In this work, the effect of silicon content and shake-out time on the grain size(GS) and hardness properties of GL 250 cast iron was studied. 
The results showed that increasing shake-out time decreased hardness and increased carbide grain size. Increasing silicon content was observed to increase grain size and reduce free graphite but with resultant decrease in hardness. Thus, grain size of carbide and hardness are both dependent on silicon content of the melt. Therefore, a particular shake-out time and silicon content can be chosen that will give desired carbide grain size and hardness for specified application material. However, graphite flake type A was obtained at 30 mins shakeout time for all samples. Two mathematical relationships were derived. One related grain-size to silicon content and shakeout time while the second related Brinnel Hardness to Silicon content and shake-out time at a pouring temperature of $1400^{\circ} \mathrm{C}$ using moulding sand of specified properties. They are:

\section{Grain Size=0.40 Si+0.17Shake-out Time-0.15 and $\mathrm{BHN=-60.53Si-7.15Shake-out} \mathrm{Time+329.35}$}

Shake-out time can be predicted using this equation if the specified pouring temperature and moulding sand properties are adhered to. Otherwise, any change in mould propertries will affect cooling rate, hence carbide grain-size. It is necessary for foundries to determine applicable relationship for their operating conditions. Combining both equations give: ShakeoutTime=6.85Grain-size-0.017Si+0.045BHN-13.19

\section{REFERENCES}

[1] Imasogie.B.I and Wendt.U(2004) 'Characterisation of graphite particle shape in spheroidal graphite iron using a computer based analyser’ JMMCE,3(1),1-12

[2] Oluwole, O.O, Olorunniwo, O.E.,Ogundare, O.O., Atanda P.O. and Oridota, O.O., (2007) 'Effect Of Magnesium And Calcium As Spheroidizers On The Graphite Morphology In Ductile Cast Iron’ JMMCE, 6(1),25-37

[3] Walton, C.F. (1958\}, Iron casting Handbook, $3^{\text {rd }}$ edition, published byIron castings society, Incorporated

[4] Krause.D.E(1969) 'Grey iron-A unique Engineering Material’ ASTM Special Technical Publication., Pholadelphia.Pp. 3-28

[5] Walton C.F and Opar T.J. (1981): "Iron casting handbook covering data on Grey, Malleable and ductile iron, Iron casting Society Inc. New York

[6] Ziegler.R(1964) 'Investigation of the influence of nucleation stage of grey iron with graphite flake’Scweizer Archives, Jan Edtn.,p.4

[7] Kehl, G. L. (1949)The Principles of Metallographic Laboratory Practice. (3rd edition). McGraw-Hill, New York, Toronto, London.

[8] Hughes, K.V.(1994) Practical Microscopical Metallography. University of Missouri Extension, Columbia Publication.

[9] Brandon, D. G. (1966)Modern Techniques in Metallography. Butterworths, London. 
[10] Greaves, R. H. \& H. Wrighton(1960) Practical Microscopical Metallography (4 ${ }^{\text {th }}$ Edition). Chapman and Hall, London.

[11] Fujita N. and Bhadeshia H. K. D. H.(1999) Mater. Sci. Tech., 15: 627 - 634.

[12] Fawole, M.O. and Oso, B.A (2001). The Principles of Metallographic Laboratory Practice. Spectrum Books Ltd, Ibadan, Nigeria.

[13] Singh.V(2005) 'Pysical Metallurgy' Standard Publishers’ p.459-462

[14] Flin. R.(1963) 'Fundamentals of Metal Casting’Addison-Lee, New-York

[15] Jain.P.L(1997)Principles of Foundry Technology’Tata McGraw-Hill, India. 